\title{
Observations of Comet 1883 Brooks-Swift at Princeton, New Jersey, U. S. A.
}

The following observations were made by myself with the $9 \frac{1}{2}$ inch refractor and ringmicrometer at the School of Science observatory. They are corrected for refraction, but not for parallax. The columns $\mathrm{C}-\mathrm{O}$ give the deviations from the orbit which follows. (Corrections made for parallax and aberration.)

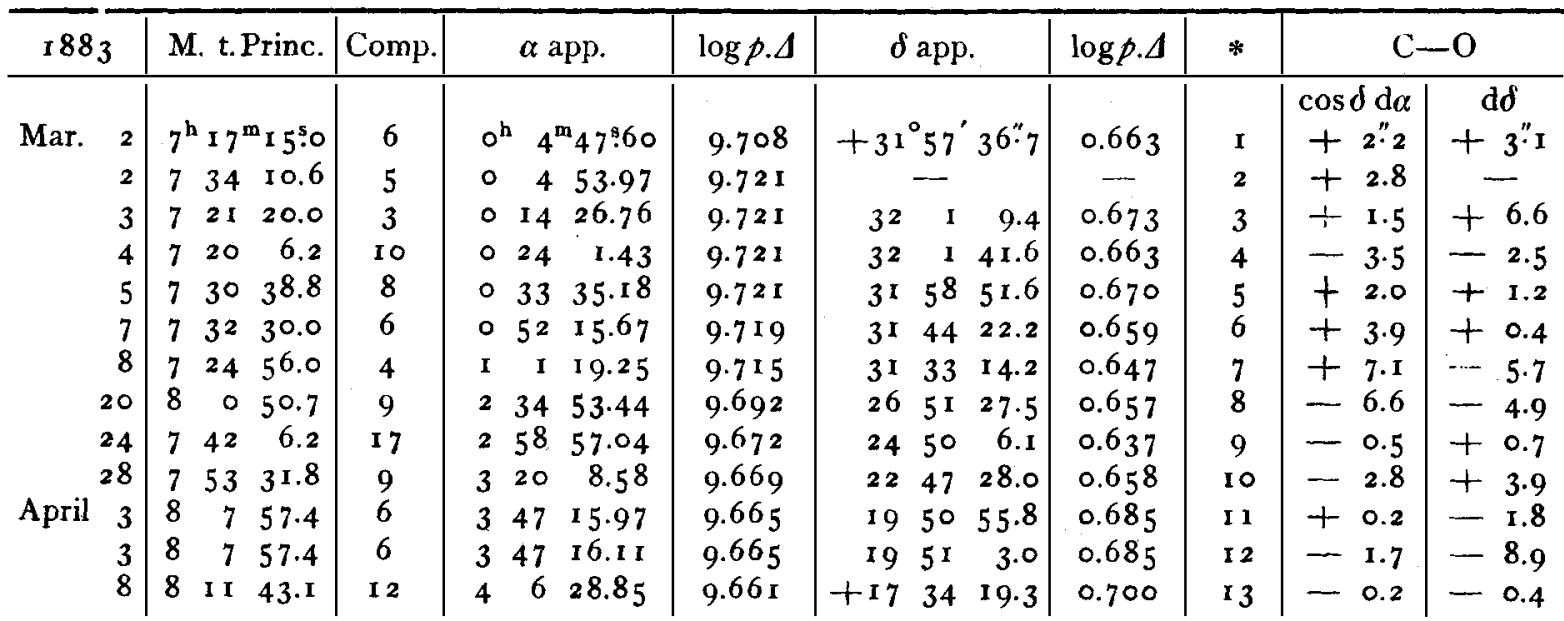

Mean Places of Comparison Stars.

\begin{tabular}{|c|c|c|c|c|c|c|c|c|c|c|}
\hline * & \multicolumn{5}{|c|}{$\alpha 1883.0$} & \multicolumn{4}{|c|}{$\delta$ I 883.0} & Authority \\
\hline $\mathbf{I}$ & $0^{h}$ & & $n_{44} \cdot 36$ & + & $0^{5} .19$ & $+3 x^{\circ}$ & $35^{\prime}$ & 29.5 & $+5 * 4$ & $W_{2} \circ^{h} 5^{1} .5^{2}$ mean \\
\hline 2 & 0 & 4 & 46.25 & + & 0.19 & 32 & I & 43.8 & +5.4 & $\mathrm{~W}_{2} \circ 5^{6.57}$ mean \\
\hline 3 & 0 & 14 & 46.80 & + & 0.23 & 32 & I9 & 52.5 & +5.5 & $W_{2} \circ 348$ \\
\hline 4 & 0 & 23 & 28.03 & + & 0.27 & 32 & 20 & 29.9 & +5.4 & $W_{2} \circ 55^{6}$ \\
\hline 5 & $\circ$ & 33 & 13.92 & + & 0.30 & $3 \mathrm{I}$ & 59 & J 2.0 & +5.3 & $W_{2} \circ 822$ \\
\hline 6 & $\circ$ & $5^{1}$ & 49.93 & + & 0.34 & $3 I$ & 22 & 56.5 & +5.0 & $W_{2} \circ$ I 296.97 mean \\
\hline 7 & 0 & 59 & 42.25 & + & 0.39 & $3 r$ & 33 & 19.3 & +4.9 & Gr. 12 X. Cat. for $1872 \mathrm{Nr} .100$ \\
\hline 8 & $\mathbf{2}$ & 36 & $35 \times 19$ & + & 0.71 & 27 & 12 & 30.0 & +1.6 & Gr. I 2 Y. Cat. for 1872 Nr. 249 \\
\hline 9 & 2 & 58 & 35.09 & + & $0.7 \mathrm{r}$ & 24 & 47 & $5^{6.2}$ & +0.1 & Wash. Obs. 1878.52 A rietis \\
\hline 10 & 3 & $2 \mathrm{I}$ & 36.20 & + & 0.75 & 22 & 23 & 58.9 & -1.4 & $1 / 3$ (Gr. $1872+$ Radcl + Yarnall $)$ \\
\hline I I & 3 & 47 & $55 \cdot 5^{6}$ & + & 0.77 & 19 & 45 & 19.2 & -3.1 & $W_{2} 3^{\mathrm{h}}$ IOI 3 \\
\hline 12 & 3 & $4^{8}$ & I 2.45 & & 0.78 & 19 & 45 & 12.2 & -3.1 & $W_{2} 31019$ \\
\hline 13 & 4 & & 54.45 & + & -0.83 & +17 & $3 \mathbf{I}$ & $57 \cdot 5$ & --4.4 & Yarn. I $80 \mathrm{r}, W_{2} 4^{\text {h }} 65$ (for proper \\
\hline
\end{tabular}

From the above positions I have deduced the following to 8 with a preliminary orbit; as second place, a position parabolic elements, using as first place a position derived derived from the observations for March 20 and 24 , and from a comparison of the observed places for March 2 the observation of April 8 as third place.

$$
\begin{aligned}
& T=\text { Febr. I 8.95349 Gr. Mean Time } \\
& \omega=110^{\circ} 54^{\prime} 4 \dot{2}^{\prime \prime} .89 \\
& \left.\begin{array}{rrrr}
\pi=29 & 2 & 48.69 \\
\delta & =278 & 8 & 5.80
\end{array}\right\} \text { Mean Equin. } 1883.0 \\
& i=78 \quad 327.71 \\
& \log q=9.8808689
\end{aligned}
$$

Princeton, N. J., 1883 May r.
Deviation of middle place: Comp.- Obs. $\cos \beta \Delta \hat{\lambda}^{\prime}-4^{\prime \prime} 8 \quad \Delta \beta^{\prime}-0 .{ }^{\prime \prime}{ }^{2}$ 